\title{
A STUDY OF REASONABLE ACCOMMODATIONS PROVIDED IN CLASSROOMS TO CHILDREN WITH SPECIFIC LEARNING DISORDERS
}

\author{
Srilakshmi Pingali ${ }^{1}$, Jayanti Sundararajan ${ }^{2}$ \\ ${ }^{1}$ Assistant Professor, Department of Psychiatry, Institute of Mental Health, Hyderabad, Consultant Psychiatrist, Roshni Counselling \\ Center. \\ ${ }^{2}$ Psychologist, Department of Psychiatry, Roshni Counselling Center.
}

\section{ABSTRACT}

\section{BACKGROUND}

Specific Learning Disorders (SLD) are a group of neurodevelopmental disorders that present with significant difficulty and underachievement in areas of reading, writing and mathematics not in keeping with the child's overall achievement level. Reasonable accommodations are one way to keep children with SLD on par with their peers as most of these accommodations are provided during examinations. Classroom study is a struggle for the child unless accommodations are provided here as well. In the absence of uniform policy, it is left to the school to provide the same.

Aim- To study the reasonable accommodations provided in classrooms to children with specific learning disorders.

Objectives-

1. To study the school policy with regard to provision of reasonable accommodations to children with specific learning disorders.

2. To study the reasonable accommodations provided in classrooms during the course of instructions.

\section{MATERIALS AND METHODS}

A total of 30 registered, privately funded, English medium schools, having up to tenth standard and willing to give written informed consent were taken up for the study. Convenience sampling method was used. A questionnaire specially designed for the study was used to collect data.

Statistical Analysis- Frequency was calculated according to descriptive statistics.

\section{RESULTS}

Majority of the schools had children with learning disability, mostly detected in classes 1-5. Nearly $76 \%$ had a uniform school policy of dealing with children having SLD. Majority of schools conducted regular awareness workshops for their teachers. Most of the accommodations provided were while providing instructions and with seating arrangements in class.

\section{CONCLUSION}

There is a policy for children with specific learning disability in exams; however, there is no uniform policy with regard to accommodations provided to such children in classrooms. Most of the schools studied had in place facilities for children in classrooms, though the lack of guidelines and uniform policy hampers their effectiveness.

\section{KEYWORDS}

Specific Learning Disorders, Classrooms, Reasonable Accommodations.

HOW TO CITE THIS ARTICLE: Pingali S, Sundararajan J. A study of reasonable accommodations provided in classrooms to children with specific learning disorders. J. Evolution Med. Dent. Sci. 2017;6(73):5195-5199, DOI: 10.14260/Jemds/2017/1129

\section{BACKGROUND \\ Specific learning disorders (SLD) are a group of neurodevelopmental disorders that present with significant difficulty and underachievement in areas of reading, writing and mathematics not in keeping with the child's overall achievement level. ${ }^{1}$ This is despite conventional instruction, intact senses, normal intelligence, proper motivation and adequate sociocultural opportunity. The term 'learning disability' was first coined in 1963 by Dr. Samuel Kirk, referring to children who reversed their letters and made other errors in their spellings. ${ }^{2}$}

Financial or Other, Competing Interest: None.

Submission 19-06-2017, Peer Review 14-07-2017,

Acceptance 19-07-2017, Published 11-09-2017.

Corresponding Author:

Dr. Srilakshmi Pingali,

Flat No. 403, Elegant Cove Apartment,

Sai Sagar Enclave, Hasmathpet,

Secunderabad-500009, Telangana.

E-mail: drpingali1@gmail.com

DOI: $10.14260 /$ jemds/2017/1129

\section{(c) (i) $(9)$}

The cornerstone of treatment of SLD is remedial education, which should ideally begin early, as the central nervous system plasticity is more in the early years.3,4

As the child grows older, accommodations are also provided along with remediation. The aim of these provisions is to help the students match their academic performance with their intellectual abilities and be on par with peers. Reasonable accommodation is defined as necessary and appropriate modification and adjustments not imposing a disproportionate or undue burden, to ensure people with disabilities the enjoyment or exercise on an equal basis with others all human rights and fundamental freedom. ${ }^{5}$ As there is no uniform policy with regards to provision of accommodations for SLD in classrooms in India, it is dependent on state policy, policy of the concerned educational board and individual school policy. These policies focus more on providing accommodations during examinations. SLD is a chronic lifelong condition and everyday learning is also a struggle for the child. Therefore, reasonable accommodations should be provided in 
classrooms as well. Children who availed the benefits of reasonable accommodation showed a significant improvement in their academic performance. ${ }^{6}$ The International Dyslexia Association has provided a list of reasonable accommodations to be provided to children in classrooms. With this background in mind, we aimed to study the reasonable accommodations provided to children with SLD in schools in Hyderabad. Hyderabad has more than 668 registered schools. ${ }^{7}$

\section{Aim}

To study the reasonable accommodations provided in classrooms to children with specific learning disorders.

\section{Objectives}

1. To study the school policy with regard to provision of reasonable accommodations to children with specific learning disorders.

2. To study the reasonable accommodations provided in classrooms during the course of instructions.

\section{MATERIALS AND METHODS}

All private schools of Hyderabad formed the universe of the study. The sampling method was convenience sampling and the study design was descriptive. The total sample size was 30. To be included in the study, the following inclusion criteria were used- the school was registered, medium of instruction was English, having classes up to tenth and willing to give informed consent. The list of registered schools was obtained and the heads of institutions contacted consecutively. All schools willing to give informed consent were taken up for the study till a total of 30 was reached. The questionnaire was administered to the head of the school or the person so assigned by the head who could give information on school policy. The questionnaire used in the study was specially designed for the same as there were no prior questionnaires to assess the same. The questionnaire had two parts. The first included general policy of the school with regards to children with specific learning disorders and the second with the accommodations provided in the classrooms during the course of instructions and the questions were based on the provisions mentioned by the International Dyslexia Association. The data so obtained was analysed.

\section{RESULTS}

A total of 30 privately funded, registered, English medium schools were taken up for the study. $53.33 \%$ of the schools followed the CBSE curriculum, followed by SSC 33.33\%. Total number of children in the classrooms ranged from 30-40. Only one school of the 30 said they did not have any children with SLD. The remaining 29 schools had children with SLD. Most of the children were detected in the primary school, which is class 1 to 5 . The age group of detection ranges from $5-10$ years. $76 \%$ of the schools had policy regarding the management of such children. Out of schools who had policy, $68 \%$ of schools had the policy of providing remedial education and $20 \%$ provided extra classes by the class teacher at the end of school hours. Majority of the schools were conducting regular workshops to raise awareness among teachers regarding learning disability. Approximately, $68 \%$ of schools had a resource room. Most schools (63\%) had the policy for continuous effort for children who did not improve. (Table 1).

Various accommodations were given to children in the classrooms. $80 \%$ of the schools have accommodation during class work in presentation of material by the teacher. Repetition of material, reading aloud and using of audiovisual aids were some of the methods commonly followed. Only $50 \%$ of the schools provided accommodations to the student while responding. Allowing oral answers instead of written work was the most common accommodation used. $80 \%$ of the schools provided accommodations in timing to complete work. Extended time to finish class work was the most commonly used method. Accommodations in seating was provided by $87 \%$ of schools. Seats nearer to teacher and seating in places in the class with minimum distractions were used. (Table 2).

\begin{tabular}{|c|c|}
\hline $\begin{array}{c}\text { Curriculum followed } \\
\text { CBSE }\end{array}$ & $\mathrm{N}(\%)$ \\
ICSE & $53.33 \%$ \\
SSC & 13.33 \\
<20 & $33.33 \%$ \\
\hline $\begin{array}{c}\text { Number class } \\
30-40 \\
>40\end{array}$ & $1(3 \%)$ \\
\hline $\begin{array}{c}\text { Are there any children with } \\
\text { SLD in schools }\end{array}$ & $15(13 \%)$ \\
\hline Yes & $10(33.3 \%)$ \\
\hline No & \\
\hline Table 1 & $29(97 \%)$ \\
\hline Which classes are they \\
often detected
\end{tabular}




\begin{tabular}{|c|c|}
\hline Modification in Presentations & \\
\hline Reading aloud & $15(50 \%)$ \\
\hline Repetition & $18(60 \%)$ \\
\hline AV aids & $14(46.67 \%)$ \\
\hline Larger print & $2(6 \%)$ \\
\hline Lesser lines per page & $7(23.33 \%)$ \\
\hline Reduce copying from board & $5(16.67 \%)$ \\
\hline Breaking question in parts & $6(20 \%)$ \\
\hline None & $6(20 \%)$ \\
\hline Modification in responses & \\
\hline Marking in question paper & $5(16.67 \%)$ \\
\hline Use of computers & $7(23.33 \%)$ \\
\hline Oral answers & $13(43.33 \%)$ \\
\hline Any other & $2($ play activity, simplified \\
\hline None & $14(46.67 \%)$ \\
\hline Timing & \\
\hline Extended time for work & $22(73.33 \%)$ \\
\hline Frequent breaks & $3(10 \%)$ \\
\hline Untimed tests & $3(10 \%)$ \\
\hline None & $6(20 \%)$ \\
\hline Seating & \\
\hline Nearer to teacher & $26(86.67 \%)$ \\
\hline Minimum distraction & $11(36.67 \%)$ \\
\hline Special lighting & 0 \\
\hline None & $4(13.33 \%)$ \\
\hline able 2. Showing Accommodations in Classrooms \\
\hline
\end{tabular}

\section{DISCUSSION}

SLD is the major cause of poor school performance with studies reporting $72 \%$ of poor school performers due to SLD. ${ }^{8}$ Its prevalence was reported from $3-15 \%$ in school children in India. 9,10

A conclusive diagnosis of SLD cannot be made until the child is about 7-8 years old, as some children are "normal late developers" and they outgrow their learning problems, unlike LD, which is a life-long disorder.11 However, signs of SLD can be detected in "at risk "children even earlier. In our study, most children were identified by the school between the ages of 5-10 years. The school curriculums followed were CBSE, ICSE and SSC.12,13,14 All three boards provide for accommodations to be provided during examinations. However, with no guidelines to provide during classroom teaching, it is mostly left to school policy. Interestingly, in our study, $76 \%$ of the schools had policy in place in dealing with children suffering from SLD. $68 \%$ of these schools provided remedial education and majority had a resource room.

The "resource room" is a place provided in the school where students with SLD receive direct, specialised instruction individually or in small groups. Remedial teachers in a resource room focus on particular goals as mandated by an Individualised Education Program and remediate general education curriculum. They also emphasise the development of executive skills, including homework completion and behaviour. Resource rooms have proven to be successful in significantly improving academic skills of children with LD. ${ }^{15,16}$

The classroom teacher and the school authorities all play a pivotal role in this direction. When perception of teachers regarding children with SLD was studied, $43.8 \%$ endorsed educating such children in special schools, while $36.3 \%$ endorsed integration to regular schools. Three fifth of teachers were willing to undergo special training for SLD intervention. ${ }^{17}$ Another study showed that knowledge among people training to be teachers was very low (exposure). ${ }^{18}$ Training of teachers will better equip them to detect and help children with SLD early. In our study, $77 \%$ of the schools were conducting regular teacher training workshops to raise awareness of teachers regarding SLD.

The International Dyslexia Association has recommended a number of accommodations that can be provided during classroom instructions. It has categorised the accommodations as accommodations involving material, accommodations involving interactive instructions, accommodations involving student performance.in accommodations involving material it has recommended simplified written instructions, repetition of material, blocking extraneous stimulation among others. In interactions, it has recommended providing lecture notes to students, using visual and auditory instructions simultaneously, writing key points on blackboard etc. Accommodations in student performance include peer mediated learning, encouraging note sharing, flexible work timings and additional practice. ${ }^{19}$ Many of the accommodations mentioned are easily applicable even in low income, overcrowded schools. Simple instructions to teachers such as seating the child near the teacher to minimise classroom distractions as some children with dyslexia also have comorbid impulsivity and attention deficits are workable solutions.

In our study, accommodations were mostly provided in interactive instructions and presentation of materials (80\%). reading aloud, repetition and presentation of material with the help of audio-visual aids were some of the commonly followed methods. Accommodation in responses were provided in only $54 \%$ of the schools. Allowing oral answers instead of written work, use of computers while answering and extended time to complete work were some of the accommodations given in response. Accommodations in seating was a commonly provided accommodation provided by $87 \%$ of schools. Seating nearer to teacher and seating in places in the class with minimum distractions were used.

\section{CONCLUSION}

The specific learning disorders are chronic lifelong conditions. They often go undetected due to low awareness. Longterm effects of these not only take a toll on the child academically but also lead to various emotional problems. Untreated learning disability leads to poor school performance which in turn causes detention or school dropout. Detention causes severe emotional stress, loss of self-esteem, withdrawn behaviour or aggression. ${ }^{20}$ The lack of achievement also adversely effects their quality of life like self-image, peer and family relationships and family interactions. ${ }^{21}$ Therefore, it is necessary not only to view SLD only from an academic perspective but an overall development of the child.

The new 'Persons with Disabilities Bill 2014', which is formulated according to the provisions in the UNCRPD has included the learning disorders in the list of disabilities and made it mandatory for education to be inclusive. ${ }^{22}$ This in turn reinforces the child's right to receive accommodations from the school. 


\section{Limitations and Future Directions}

Small sample size and inclusion of privately funded schools only may limit the generalisation of the findings to other schools. Making accommodations mandatory, holding regular awareness workshops for class teachers and empowering parents with information to help them advocate for the rights of their child will go a long way in helping children having SLD.

\section{Questionnaire used in the Study}

1. Curriculum followed in school-ICSE/CBSE/SSC

2. Average number of children in each class

3. Are there any with SLD in your school?

4. Which classes are they most often detected.

5. Do they have any school policy regarding these children?

6. If yes -what is it?

7. Are there regular workshops conducted for teachers to raise their awareness

8. Is there a resource room provided in the school?

9. What happens to children who do not improve?

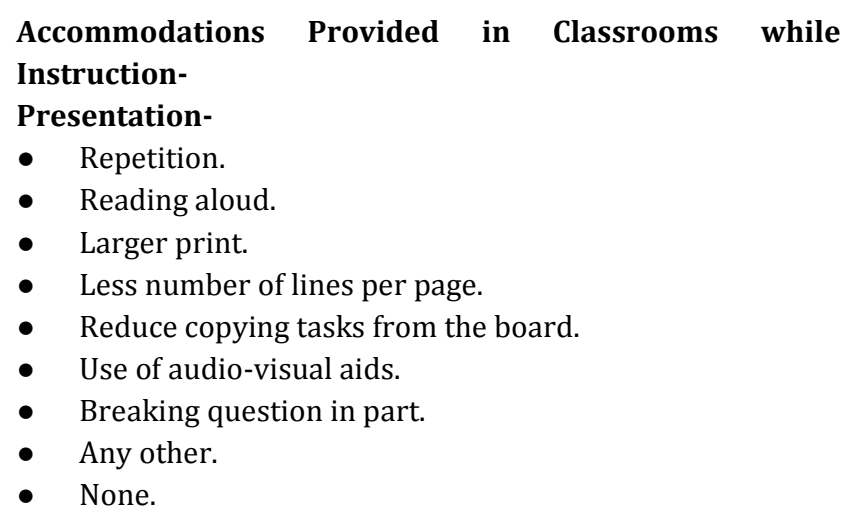

\section{Responses-}

- Marking responses in question paper.

- Use of computers.

- Oral answers.

- Any other.

- None.

\section{Timing-}

- $\quad$ Extended time for work.

- Frequent breaks.

- Untimed tests.

- Any other.

- None.

\section{Seating-}

- Nearer to teacher.

- Minimum distraction.

- Special lighting.

- Any other.

- None.

\section{ACKNOWLEDGMENT}

We wish to acknowledge the constant support and guidance of Dr. Soumitra Pathare throughout the preparation of this article.

\section{REFERENCES}

[1] American Psychiatric Association. Diagnostic and statistical manual of mental disorders. $5^{\text {th }}$ edn Arlington, VA: American Psychiatric Publishing 2013.

[2] Karande S, Kulkarni M. Specific learning disability the invisible handicap. Indian Pediatr 2005;42(4):315-9.

[3] Alexander AW, Slinger-Constant AM. Current status of treatment of dyslexia: critical review. J Child Neurol 2004;19(10):744-58.

[4] Saravanabhavan S, Saravanabhavan RC. Attitudes toward disabilities across cultures. Educ Pract and Theory 2001;23(2):49-60.

[5] UN General Assembly, Convention on the rights of persons with disabilities : resolution / adopted by the General Assembly, 24 January 2007, A/RES/61/106, http://www.refworld.org/docid/45f973632.html

[6] Kulkarni M, Karande S, Thadhani A, et al. Educational provisions and learning disability. Indian J Pediatr 2005;72:1029-33.

[7] List of schools in AP. 2011 http://www.aponline.gov.in/Apportal/ schools.html

[8] Karande S, Doshi B, Thadhani A, et al. Profile of children with poor school performance in Mumbai. Indian Pediatr 2013;50(4):427.

[9] Padhy SK, Goel S, Das SS, et al. Prevalence and patterns of learning disabilities in school children. Indian J Pediatr 2016;83(4):300-6.

[10] Mogasale VV, Patil VD, Patil NM, et al. Prevalence of specific learning disabilities among primary school children in a South Indian city. Indian J Pediatr 2012;79(3):342-7.

[11] Karande S, Sholapurwala R, Kulkarni M. Managing specific learning disability in schools in India. Indian Pediatr 2011;48(7):515-20.

[12] http://www.cbse.nic.in/ on 15th July 2011.

[13] http://www.cisce.org/ on 15th July 2011-09-11.

[14] Government of Andhra Pradesh. Abstract SSC Public Examinations - Recommendations for amendments in Examination Rules of State Board of Education for allowing extra time during examinations, 3rd language exemption and scribed for students who suffer from Dyslexia - Orders - Issued. EDUCATION (SE-EXAMS) DEPARTMENT; G.O.Ms.No.34 Dt.5-3-2004 Read:- From the C \& DSE, Rc.No.56/E1-2/2003, dt.7-8-2003.

[15] Idol L. Toward inclusion of special education students in general education: a program evaluation of eight schools. Remedial Spec Educ 2006;27(2):77-94.

[16] Menzies HM, Mahdavi JN, Lewis JL. Early intervention in reading: From research to practice. Remedial Spec Educ 2008;29(2):67-77.

[17] Padhy SK, Goel S, Das SS, et al. Perceptions of teachers about learning disorder in a northern city of India. J Family Med Prim Care 2015;4(3):432-4.

[18] Saravanabhavan S, Saravanabhavan RC. Knowledge of learning disability among pre and in service teachers in India. International Journal of Special Education 2010;25(3):132-8.

[19] The International Dyslexia Association (IDA) 2002. Fact Sheet \#51 -10/02. 2011. 
[20] Pagani L, Tremblay RE, Vitaro F, et al. Effects of grade retention on academic performance and behavioural development. Dev Psychopathol 2001;13(2):297-315.

[21] Karande S, Bhosrekar K, Kulkarni M, et al. Health related quality of life of children with newly diagnosed specific learning disability. J Trop Pediatr 2009;55(3): 160-9.
[22] http://www.prsindia.org/billtrack/the-right-of persons-with-disabilities-bill-2014-3122/ 2017. 